\title{
Mitochondrial Mutations in Essential Hypertension
}

\author{
Haiyan Zhu and Shiwen Wang \\ General Hospital of Chinese PLA
}

China

\section{Introduction}

Hypertension is a common condition, a risk factor for heart disease, renal failure and stroke, affecting approximately 1 billion individuals worldwide and 200 million in China[1, 2]. Thus, understanding the underlying etiology of hypertension has been a major research focus, especially the genetics of essential hypertension (EH), large proportion of hypertension. Indeed, since the completion of the draft sequence of human genome, geneticists have announced that within 10 years they expect to determine the significance of the genome as related to essential hypertension[3]. Some progress has been made. For example, for systolic blood pressure alone, 27 nuclear loci have been identified in populations of European and African ancestry[3]. However, to date no consistent results have been obtained across ethnicity and races supporting the need for genetic studies in diverse populations ${ }^{[4-8]}$.

While the nuclear genome has been studied extensively with respect to hypertension, much less work has been done with the mitochondrial genome (mtDNA). Yet there is evidence to suggest that mitochondria and mtDNA may be important in hypertension. For example, mitochondria produce reactive oxidative species (ROS) and these ROS can cause hypertension [9-11]. With respect to the evidence of mtDNA, a hallmark of involvement of mtDNA is maternal inheritance. Multiple studies have identified strong maternal inheritance of blood pressure, with one study suggesting that over one-third of hypertension could be attributed to mtDNA variation [12-14]. Interestingly, a variant in mitochondrial tRNA Ile has been identified in a single family which segregated with hypertension and appeared causal [15]. Taken together, this work suggests the importance of looking at mtDNA variation to further our understanding of the underlying etiology of $\mathrm{EH}$.

\section{Mitochondria}

\subsection{Biogenesis and bioenergetics}

Matrilineal inheritance in EH pedigrees support the hypothesis that mitochondrial genes are also implicated in the pathogenesis of EH. Mitochondria evolved from protobacteria that inhabited primordial eukaryotic cells about 1.5 billion years ago and were first observed more than100 years ago by Altmann. It's a small symbiotic $(0.5-1 \mu \mathrm{m})$ organelle combined with aerobic bacteria and primordial eukaryotic cells. 37 genes make up a mitochondrion within which thousands of mtDNA forming double-stranded 16569 base-pair.(Fig. 1) Of 
these genes, 24 encode RNAs necessary for protein synthesis (22 tRNAs and 2 rRNAs), The remaining 13 genes encode proteins that are critical subunits of the respiratory chain.

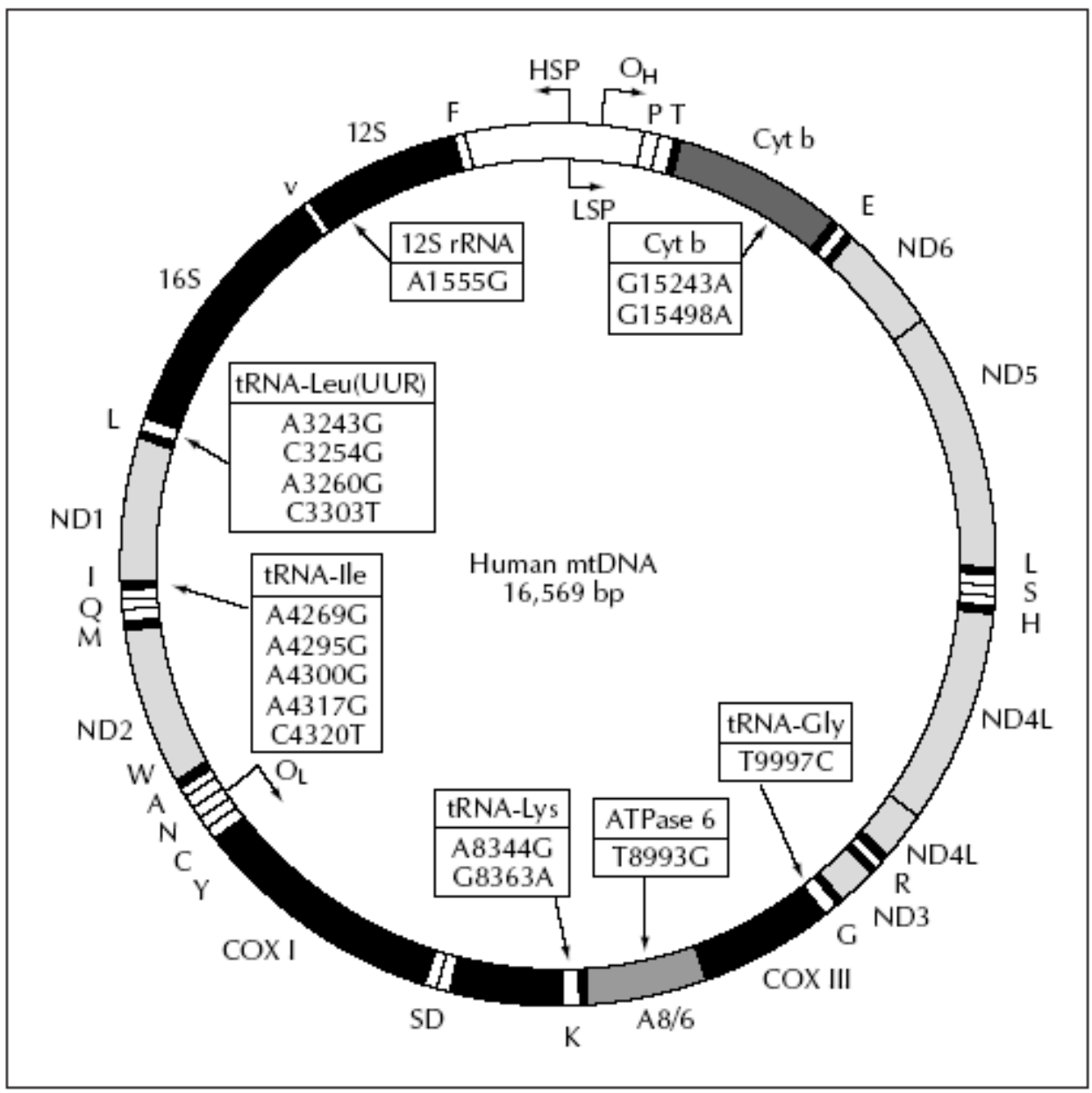

Fig. 1. Human mitochondrial DNA (mtDNA) map showing location of selected pathogenic mutations associated with left ventricular hypertrophy or hypertrophic cardiomyopathy. Human mtDNA is a 16569 base pair circular molecule that codes for $7(\mathrm{ND} 1,2,3,4,4 \mathrm{~L}, 5$ and 6 ) of 43 subunits of complex I; 1 (cytochrome b) of 11 subunits of complex III; 3 (COI, II and III) of 13 subunits of complex IV; and 2( ATPase 6 and 8) of 16 subunits of complex V. It also codes for small and large rRNAs and 22tRNAs, with adjacent letters indicating cognate amino acids. (Adapted from Hirano $\mathrm{M}$ et al. Mitochondria and the heart. Current Opinion in Cardiology 2001, 16:201-210.) 
The mitochondrion contains an inner and an outer membrane which defines the matrix and the intermembrane space. The outer membrane is permeable to small molecules (up to $10 \mathrm{kDa}$ ) whereas the inner membrane is freely permeable to oxygen and carbon dioxide. This relative impermeability of the inner membrane is essential for maintaining a proton gradient necessary for the synthesis of adenosine triphosphate (ATP). There are several unique features of mtDNA and mitochondrial genetics which are distinct from the features of nuclear genes and the principles of nuclear inheritance. First, mammalian mtDNA does not contain introns which make mtDNA mutations affect phenotype of diseases much more easily comparing to nuclear genes. Second, several mitochondrial genetic codons differ from the universal nuclear genetic code. UCG codes for tryptophan and not termination, AUA codes for methionine not isoleucine, and AGA and AGG are termination rather than arginine codons. AUA are possibly AUU are initiation codons as well as AUG. Third, only the mother contributes to the mtDNA pool of the offspring, It dues mostly to the fact to a large extent that sperm contains only $100 \mathrm{mtDNA}$ while egg contains approximately 10,000 mtDNA[16]. Fourth, the fixation of mtDNA mutations is more than 10 times higher in comparison with the nuclear DNA mutation rate [17]. A possible explanation for this difference is the lack of protective histones and the absence of effective DNA repair systems within mitochondria. In addition, by being exposed to tremendous fluxes of oxygen, mtDNA may also be a target for the reactive oxygen species produced as by-products of oxidative phosphorylation. Fifth, an individual may carry several allelic forms of mtDNA, present in different proportions in different tissues [18,19]. The coexistence of more than one type of mtDNA within a cell, wide-type accompany with mutant type, is called heteroplasmy. Sixth, there is as yet no conclusive evidence demonstrating that orthodox recombination occurs between individual mtDNA molecules. New mtDNA alleles can thus only arise through spontaneous mutations. In spite of striking difference of morphological and inherited characteristics from nuclear genes, mitochondria have three major functions which associated with pathogenesis of diseases synergically. (energetic, reactive oxygen species, apoptosis). First, mitochondria offer about $90 \%-95 \%$ energy to cells through oxidative phosphorylation(OXPHOS). Five multipolypeptide enzyme complexes make up OXPHOS(Fig.2) as follows.: Complex I(NADH:ubiqunone oxidoreductase), II(succinate: uiquinone oxidoreductase), III(ubiquinol: ferrocytochrome C oxidoreductase), IV (cytochrome C oxidase) constitute electron transport train(ETC).Through ETC, energy is released to pump protons from inside the mitochondrial matrix across the mitochondrial inner membrane into the intermembrane space. And the electrochemical gradient $(\triangle \psi)$ results from ETC offers energy for complex $\mathrm{V}\left(\mathrm{H}^{+-}\right.$translocating ATP synthase) to produce adenosine triphosphate.

Second, toxic by-products, reactive oxygen species(ROS) including $\mathrm{O}_{2}{ }^{-}, \mathrm{H}_{2} \mathrm{O}_{2}$ and $\cdot \mathrm{OH}$, derived from mitochondrial OXPHOS do harm to cells to variable extents according to different period of time exposure to ROS. Short-term exposure to ROS can reduce the activity of ETC and slow down the metabolism while long-term exposure will induce irreversible oxidative damage thus cause markedly reduction of mitochondrial function. 
Third, mitochondria are implicated in the initiation of apoptosis in specific circumstances through opening mitochondrial permeability transition pore (mtPTP) within the membrane. Program cell death activates for the leaking of apoptosis-promoting factors located in matrix such as cytochrome c. apoptosis-initiation factor(AIF) and kinds of caspases by mtPTP.

\subsection{Mitochondria and heart diseases}

For the three basic functions of mitochondria indicated above, the hypothesis of mitochondria participates in pathogenesis of heart diseases have been supported by both experimental and clinical evidences.

In 1988, the first disease-causing mutation of mtDNA were found that patients with mitochondrial myopathy identified a variety of functional defects of the mitochondrial respiratory chain, predominantly affecting complex I (NADH-CoQ reductase) or complex III (ubiquinol-cytochrome $\mathrm{c}$ reductase) in adult cases[20,21].This discovery led to a rapid surge in the research into mitochondrial disorders, and there are now more than 200 different mtDNA mutations linked to human disease (http://www.mitomap.org) Given the fact that heart is a second largest oxygen-consumed organ within body with $12 \%$ oxygen necessary to work averagely just less than brain, it follows that heart should be a harrowing victim for oxygen deficiency in vivo. Actually, Every heart beat consumes $2 \%$ of total cellular ATP. And $90 \%$ of its ATP is produced by mitochondrial oxidative phosphorylation. Thus, mitochondria are assumed to be implicated in the pathogenesis of multiple cardiovascular diseases, with regard to the basic functions of the organelle[22].

Mitochondria are found to influence all of the four major features of cadiomyocytes: excitability, contractility, conductibility and autorhythmicity to certain degree. The rate and force of contraction of heart muscle change according to ATP utilization. Patients with mtDNA deletions named sporadic rearrangements often develop atrioventricular blocks, which progress from mild to severe (type I to type III )[23, 24], respectively. Kearns-Sayre Syndrome (KSS) and Chronic Progressive External Ophthalmoplegia(CPEO) are the major multisystemic disorders which affect cardiac conductive system particularly. Diversity of cardiac conduction defects including prolonged intraventricular conductiontime, bundlebranch block, and atrioventricular block often lead to sudden cardiac death. 4.9kb "common" deletion loci from ATP6 through COIII, ND3, ND4L, ND4, to ND5 contribute to KSS[25]. While A3243G mutation associates with maternally inherited PEO with RRF[26] and diabetes and deafness[27].Aon MA, et al introduced a novel conception "mitochondrial criticality" to describe the state in which the mitochondrial network of cardiomyocytes becomes very sensitive to small perturbations in reactive oxygen species (ROS), resulting in the scaling of local mitochondrial uncoupling and $\Delta \Psi_{\mathrm{m}}$ loss to the whole cell, and the myocardial syncytium. The energetic changes are translated into effects on the electrical excitability of the cell, inducing temporal heterogeneity of excitability in the heart, underlies the genesis of potentially lethal cardiac arrhythmias [28].

Except for arrhythmia and excitability, mitochondrial dysfunction has also been suggested to reduce contraction of heart thus result in heart failure and age-associated decline in heart function [29-32]. 


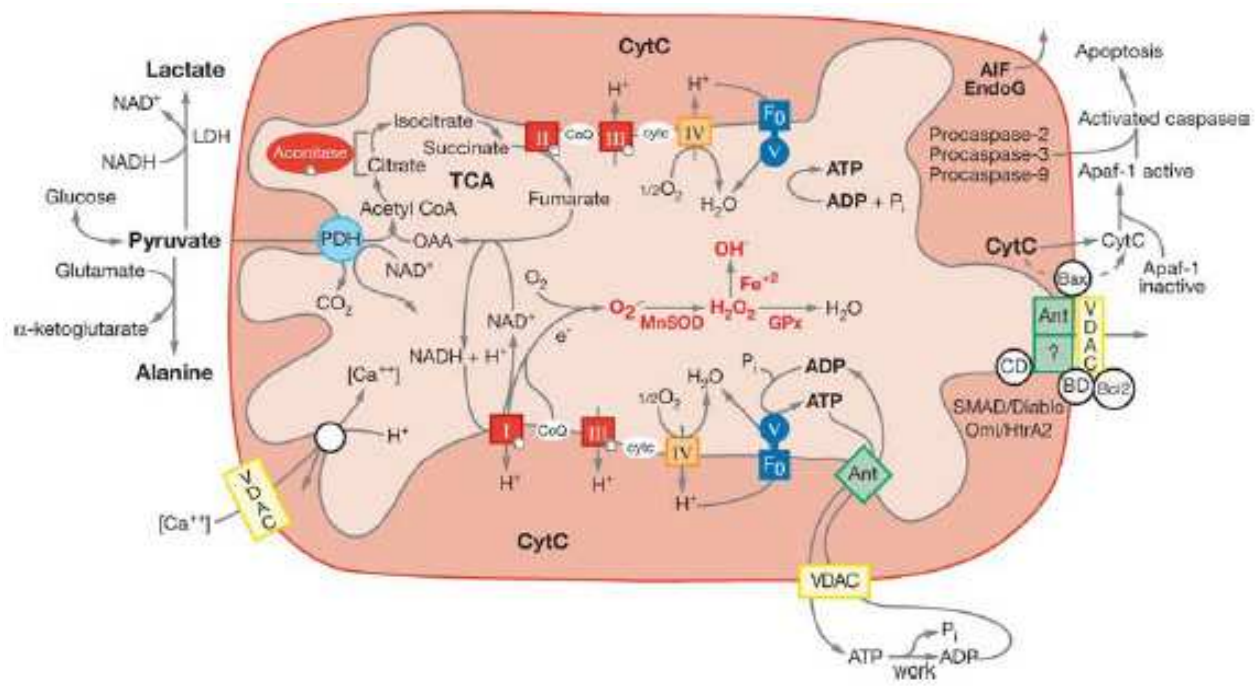

Fig. 2. Diagram showing the relationships of mitochondrial oxidative phosphorylation (OXPHOS) to (a) energy (ATP) production, (b) reactive oxygen species (ROS) production, and (c) initiation of apoptosis through the mitochondrial permeability transition pore (mtPTP). The OXPHOS complexes, designated I to $\mathrm{V}$, are complex I (NADH: ubiquinone oxidoreductase) encompassing a FMN (flavin mononucleotide) and six Fe-S centers (designated with a cube); complex II (succinate: ubiquinone oxidoreductase) involving a FAD (flavin adenine dinucleotide), three Fe-S centers, and a cytochrome b; complex III (ubiquinol: cytochrome c oxidoreductase) encompassing cytochromes b, $\mathrm{c} 1$ and the Rieske Fe-S center; complex IV (cytochrome c oxidase) encompassing cytochromes a + a3 and $\mathrm{CuA}$ and CuB; and complex V (H+-translocating ATP synthase). Pyruvate from glucose enters the mitochondria via pyruvate dehydrogenase (PDH), generating acetylCoA, which enters the TCA cycle by combining with oxaloacetate (OAA). Cis-aconitase converts citrate to isocitrate and contains a $4 \mathrm{Fe}-4 \mathrm{~S}$ center. Lactate dehydrogenase (LDH) converts excess pyruvate plus NADH to lactate. Small molecules defuse through the outer membrane via the voltage-dependent anion channel (VDAC) or porin. The VDAC together with ANT, Bax, and the cyclophilin $\mathrm{D}(\mathrm{CD})$ protein are thought to come together at the mitochondrial inner and outer membrane contact points to create the mtPTP. The mtPTP interacts with the proapoptotic Bax, anti-apoptotic Bcl2 and the benzodiazepine receptor (BD). The opening of the $\mathrm{mtPTP}$ is associated with the release of several pro-apoptotic proteins. Cytochrome $\mathrm{c}$ (cytc) interacts with and activates cytosolic Apaf-1, which then binds to and activates procaspase9. The activated caspase- 9 then initiates the proteolytic degradation of cellular proteins. Apoptosis initiating factor (AIF) and endonuclease G (EndoG) have nuclear targeting peptides that are transported to the nucleus and degrade the chromosomal DNA. (Adapted from Wallance DC. Mitochondrial diseases in man and mouse. Science. 1999;283:1482-8.) 


\section{Genetic basis of EH}

\subsection{Nuclear genes}

Previous studies of hypertension in humans and experimental animal models have identified a number of candidate genes that have been implicated as possibly contributing to essential hypertension. The renin-angiotensin-aldosterone system may play a prominent role in the genesis of hypertension, and polymorphisms of the genes coding for angiotensinogen, angiotensin-converting enzyme, angiotensin II type 1 and 2 receptors, and aldosterone synthase have been widely studied. Other mechanisms may involve the KLK 1 gene of tissue kallikrein, gene variants of endothelial nitric oxide synthase and polymorphisms of the endothelin-1 gene. A number of studies have highlighted the potential contribution of polymorphisms of genes coding for inflammatory cytokines, adrenergic receptors and intracellular $\mathrm{G}$ proteins, which can activate $\mathrm{Na}+/ \mathrm{K}+$ exchangers. Multiple researches found that the genetic findings may vary greatly according to the populations studied and the causal relationship between candidate genes and EH were difficult to establish firmly[33-35]. Further studies found that mitochondrial variants in EH were heatedly discussed in late 5 years.

\section{Mitochondrial genes}

\subsection{Clinical researches of mtDNA mutation in EH}

Schwartz $\mathrm{F}$, et al[36] investigated the contribution of the mitochondrial genome to hypertension and quantitative blood pressure (BP) phenotypes in the Framingham Heart Study cohort. Longitudinal BP values of 6421 participants (mean age, 53 years; $46 \%$ men) from 1593 extended families were analyzed. The role of mitochondrial influence in the hypertensives was 35.2\% (95\% confidence interval, $27-43 \%, \mathrm{P}<10$ ) The mitochondrial heritabilities for multivariable-adjusted long-term average systolic BP and diastolic BP were, respectively, $5 \%(\mathrm{P}<0.02)$ and $4 \%(\mathrm{P}=0.11)$. Schwartz $\mathrm{F}$, et al [37] compared maternal and paternal contributions to the familial aggregation of hypertension in 344 hypertensive probands.Among them, 69 were African American, 153 US Caucasian, 122 Greek Caucasian. It was found that the proportion of hypertensive mothers $(81.7,65.0$ and $84.8 \%$ for African Americans, US Caucasians and Greek Caucasians, respectively) of these probands was significantly greater than the proportion of hypertensive fathers $(50.0,44.9$ and $48.3 \%$, respectively) in all three ethnic groups. The lifetime risk of hypertension was significantly greater for mothers compared with fathers of these hypertensive probands $(\mathrm{p}<0.001)$. Examination of the proband's siblings indicated that maternal history of hypertension was associated with greater lifetime risk for hypertension than paternal history $(p<0.01)$. Thus, it drew the conclusion maternal influence on blood pressure suggested involvement of mitochondrial DNA in the pathogenesis of EH. Muscari A, et al [38] hypothesized that hypertension is a condition resulted from elevated levels of reactive oxygen (ROS) and nitrogen (RNS) species. Mitochondria are important sites of ROS production, and a mitochondrial dysfunction, preceding endothelial dysfunction, might favor the development of hypertension. ROS production may also be induced by RNS, which inhibit the respiratory chain and may be generated through the action of a mitochondrial NO synthase. Mitochondrial uncoupling proteins are involved in both 
experimental and human hypertension. Finally, an excessive production of ROS may damage mitochondrial DNA, with resultant impairment in the synthesis of some components of the respiratory chain and further ROS production, a vicious cycle that may be implicated in hypertensive states.

\section{Our studies of mtDNA mutation in EH}

To determine the relationship between mitochondrial genomic variation and essential hypertension, we performed a systematic and extensive screening of mitochondrial genes at the Institute of Geriatric Cardiology, Chinese PLA General Hospital in a large Chinese cohort. We focused on this Chinese population because of the high morbidity of essential hypertension in Chinese adults (nearly $11.8 \%)^{2}$ and the limited amount of research on this racial group. We used a population instead of family-based strategy for two reasons: 1) Large numbers of hypertensives without family history are not detected in China, and they might be overlooked for lacking of medical knowledge and regular checks. 2) The morbidity of essential hypertension is not totally family-based; $50-60 \%$ of hypertensives are sporadically distributed. ${ }^{2}$

We sequenced mitochondrial genomes in 306 age and gender balanced Chinese hypertensives and controls. In the 153 hypertensives, putative functional changes included 4 changes in rRNA genes, 11 changes in tRNA genes and 25 amino acid substitutions. The remaining variants were synonymous changes or non-coding regions. In the 153 controls, 1 base change in the tRNA genes and 8 amino acid substitutions were found. A8701G in ATP6 gene (belongs to haplogroup $\mathrm{M})(\mathrm{P}=0.0001)$ and $\mathrm{C} 8414 \mathrm{~T}$ in ATP8 gene (belongs to haplogroup D) ( $\mathrm{P}=0.0001)$ were detected significantly different in the cases and controls. Interestingly, the cases were more likely to have two or more amino acid changes and RNAs variants as compared to the controls $(24.75 \%$ versus $7.94 \%, \mathrm{P}=0.0001)$. In addition, several variants were highly conserved and/or specifically located at the $3^{\prime}$ end adjacent to the anticodon, which may contribute to the stabilization of structure thus lead to the decrease of tRNA metabolism. In the cohort of hypertensives, there were several variants that occurred too infrequently to have sufficient statistical power but that have biologic plausibility. T4363C localized at the $3^{\prime}$ end adjacent to the anticodon, which contributed to the stabilization of structure thus lead to the decrease of tRNA metabolism. A4263G at the initial part of tRNAIle may influence the transcription of tRNA herein affect the steady-level of protein synthesis. And some other novel RNAs variants (C3168CC, G3173A, A3203G, T3290C, A4263G, T4363C, C4410A, T8311C) in 16s RNA, tRNALeu(UUR), tRNAlle, tRNAMet, tRNAGln and tRNALys only found in hypertensives but not controls. In coding regions, even though a novel point variant G8720C in ATP6 gene, with high conservation among species was not significant in epidemiological perspective. Synergetic interaction between mitochondrial mtSNPs and/or haplogroups is needed to be investigated in the future[39]. Sequence analysis then performed in tRNA genes, hot spots for cardiovascular diseases, in 270 Chinese Han essential hypertensives and 270 controls. Lymphoblastoid cell lines were immortalized by transformation with the Epstein-Barr virus. Rates of oxygen consumption in intact cells were determined with a YSI 5300 oxygraph (Yellow Springs Instruments) on samples, harboring variants in tRNA genes. In the study, environmental factors including 
age, gender, BMI, fasting blood sugar and blood lipids, contributing a lot to high blood pressure [40,41] didn't exhibit difference between cases and controls. It was presumed that hereditary factors may associate with the pathogenesis of hypertension in the Chinese Han population. There were 26 variants in tRNA genes were found in hypertensives and these variants were not in controls. Functional analysis found that these variants may lead to deficiencies in tRNA $3^{\prime}$ end metabolism (3' end cleavage, CCA addition and aminoacylation) and/or impairment of critical subunits of the respiratory chain, which help understanding of molecular mechanisms of mitochondrial tRNA genes in essential hypertension as follows: C3254T and A8348G mildly reduced the efficiency of aminoacyltRNA synthetase (aaRS) [42]; A4295G reduced efficiency of tRNA 3'-processing endoribonuclease (tRNAseZ) and aaRS [43]; A4317G reorganized T-stem which markedly reduced the efficiency of tRNA 3'-processing endoribonuclease tRNAseZ, aaRS, and tRNA nucleotidyl transferase (CCAse) [44]. The other possible effects of tRNA mutations on tRNA modifications may be the reduction of efficiency of the binding properties of aminoacyl-tRNAs to mitochondrial elongation factor Tu (Ef-Tu) [45]. All of the above variants influenced the process of aminoacylation which affected tRNA metabolism and impaired the synthesis of protein ultimately. Most importantly, eight of these variants were highly conserved from bacteria to human beings (A4263G, A4295G, A4316TA, A4343G, A4388G, C4392T, C4410A and A4435G) thus minor changes in charge or structure may result in impairment of translation and affect the synthesis of protein. In addition, A4295G, A4435G and T4363C all localized at the 3' end adjacent to the anticodon, which contributed to the stabilization of structure thus lead to the decrease of tRNA metabolism. Otherwise, a novel variant A4263G at the initial part of tRNAlle may influence the transcription of tRNA herein affect the steady-level of protein synthesis. It also possible that such mutations could affect the tRNAs correct decoding of the mRNA in the ribosome (by increase in frameshifting for example) and, particularly in the case of T4363C, could also interfere with aminoacylation, since glutaminyl-tRNA synthetases are known to interrogate the anticodon loop of tRNAGln during catalysis [46]. And some other novel tRNA variants (T4277C, T4353C, C4410A, T8311C) in tRNALeu(UUR), tRNAlle, tRNAMet, tRNAGln and tRNA ${ }^{\text {Lys }}$ need to be further investigated in the future. Interestingly, functional analysis found significant reduction of oxygen consumption rate in two mutant cell lines carrying variants T4454C and A4263G. Oxygen consumption is a classical means of assessing energy expenditure, one component of energy balance [47, 48]. Cells and organisms are able to trigger an adaptive response to hypoxic conditions that is aimed to help them to cope with these threatening conditions [49]. Failing to keep the balance of oxygen consumption and production may cause cardiovascular diseases and is of particular significance in the pathogenesis of essential hypertension. A variant in mitochondrial tRNAlle has been identified in a single family which segregated with hypertension and appeared causal [14]. Interestingly, we deduced that except the A4263G and $\mathrm{T} 4454 \mathrm{C}$ variants, there were other amino acid changes may contributing to hypertension by entire mitochondrial genome sequencing of the cells. This finding would suggest that there may be a threshold effect with some of these mtDNA variants. Such that often variability at a single locus will not be sufficient to increase hypertension risk. This is consistent with previous work that essential hypertension is controlled by multiple 
genetic loci, each with a relatively weak effect in the population at large [50]. Most importantly, the oxygen consumption rate in cells harboring variants $\mathrm{T} 4454 \mathrm{C}(\mathrm{P}=0.0010)$ and A4263G ( $\mathrm{P}=0.0001)$ decreased as compared to the average level of control cell lines. The findings suggested that variants located in mitochondrial tRNA genes may have biologic plausibility to implicate in the pathogenesis of Chinese essential hypertension.

\section{Prospects}

The mitochondrial influence in $\mathrm{EH}$ remains a lot of questions to be answered. The mitochondrial variants always seem to be infrequent and perhaps even private, relationship between nuclear genes and mitochondrial genes is obscure, enviromental influence somehow affects results of studies of mitochondria. All in all, there's still a long way to go to disclose the secret of mitochondria and $\mathrm{EH}$.

\section{References}

[1] Chobanian AV, Bakris GL, Black HR, et al. The Seventh Report of the Joint National Committee on Prevention, Detection, Evaluation, and Treatment of High Blood Pressure: the JNC 7 report. Jama 2003; 289:2560-72.

[2] Liu LS. 2005 Guidelines for prevention and treatment of hypertension in China. People's medical publishing house, Beijing, 2007; pp 1-8.

[3] Harrap SB. Where are all the blood-pressure genes? Lancet 2003; 361:2149-51.

[4] Bonnardeaux A, Davies E, Jeunemaitre X, et al. Angiotensin II type 1 receptor gene polymorphisms in human essential hypertension. Hypertension 1994; 24:63-9.

[5] Caulfield M, Munroe P, Pembroke J, et al. Genome-wide mapping of human loci for essential hypertension. Lancet 2003; 361:2118-23.

[6] Kamide K, Kokubo Y, Fukuhara S, et al. Protein tyrosine kinase 2beta as a candidate gene for hypertension. Pharmacogenet Genomics 2007; 17:931-9.

[7] Banno M, Hanada H, Kamide K, et al. Association of genetic polymorphisms of endothelin-converting enzyme-1 gene with hypertension in a Japanese population and rare missense mutation in preproendothelin-1 in Japanese hypertensives. Hypertens Res 2007; 30:513-20.

[8] Kulah E, Dursun A, Aktunc E, et al. Effects of angiotensin-converting enzyme gene polymorphism and serum vitamin $\mathrm{D}$ levels on ambulatory blood pressure measurement and left ventricular mass in Turkish hypertensive population. Blood Press Monit 2007; 12:207-13.

[9] Wallace DC. Mitochondrial diseases in man and mouse. Science 1999; 283:1482-8.

[10] Hirano M, Davidson M, DiMauro S. Mitochondria and the heart. Curr Opin Cardiol 2001; 16:201-10.

[11] Lassègue B, Griendling KK. Reactive oxygen species in hypertension; An update. Am J Hypertens 2004;17:852-60.

[12] Hutchinson, J., Crawford, M.H. Genetic determinants of blood pressure level among the Black Caribs of St Vincent. Human Biology 1981; 53:453-66.

[13] DeStefano AL, Gavras H, Heard-Costa N, et al. Maternal component in the familial aggregation of hypertension.Clin Genet 2001;60:13-21. 
[14] Yang Q, Kim SK, Sun F, et al. Maternal influence on blood pressure suggests involvement of mitochondrial DNA in the pathogenesis of hypertension: the Framingham Heart Study. J Hypertens 2007; 25:2067-73.

[15] Wilson FH, Hariri A, Farhi A, et al. A cluster of metabolic defects caused by mutation in a mitochondrial tRNA. Science 2004; 306:1190-4.

[16] Zeviani M, Bonilla E, Devivo DC, Dimauro S. Mitochondrial diseases. Neurol Clin. 1989, 7:123-56.

[17] DiMauro S, Moraes CT. Mitochondrial encephalomyopathies. Arch Neurol. 1993, 50:1197-208

[18] Singh MM, Sinha A. Mitochondrial diseases: relevance to a physician. Postgrad Med. 1998, 12:148-61

[19] Vladutiu GD. Advances in the genetic mechanism of mitochondrial diseases. Curr Opin Neurol. 1997, 10:512-8.

[20] Holt IJ, Harding AE, Morgan-Hughes JA. Deletions of muscle mitochondrial DNA in patients with mitochondrial myopathies. Nature. 1988, 331: 717-9.

[21] Wallace DC, Singh G, Lott MT et al. Mitochondrial DNA mutation associated with Leber's hereditary optic neuropathy. Science. 1988, 242: 1427-30.

[22] Harris DA, Das AM.Control of mitochondrial ATP synthesis in the heart. Biochem J. 1991, 280:561-73.

[23] Hirano M, DiMauro S: Clinical features of mitochondrial myopathies and encephalomyopathies. In Handbook of Muscle Disease. Edited by Lane RJM. New York: Marcel Dekker Inc. USA, 1996,479-504.

[24] Moraes CT, Shanske S, Tritschler HJ, et al.: MtDNA depletion with variable tissue expression: A novel genetic abnormality in mitochondrial diseases. Am J Hum Genet. 1991, 48:492-501.

[25] Alemi M, Prigione A, Wong A, Schoenfeld R, et al. Mitochondrial DNA deletions inhibit proteasomal activity and stimulate an autophagic transcript. Free Radic Biol Med. 2007, 1,42(1):32-43.

[26] Moraes CT, Ciacci F, Silvestri G, et al. Atypical clinical presentations associated with the MELAS mutation at position 3243 of human mitochondrial DNA. Neuromusc Disord. 1993, 3:43-50.

[27] van den Ouweland JM, Lemkes HH, Ruitenbeek W, et al. Mutation in mitochondrial tRNA(Leu)(UUR) gene in a large pedigree with maternally transmitted type II diabetes mellitus and deafness. Nat Genet. $1992,1(5): 368-71$.

[28] Aon MA, Cortassa S, Akar FG, O'Rourke B. Mitochondrial criticality: a new concept at the turning point of life or death. Biochim Biophys Acta. 2006 ,1762(2):232-40.

[29] Hattori K, Tanaka M, Sugiyama $S$ et al. Age-dependent increase in deleted mitochondrial DNA in the human heart: possible contributory factor to presbycardia. Am Heart J. 1991, 121: 1735-42.

[30] Melov S, Shoffner JM, Kaufman A, et al. Marked increase in the number and variety of mitochondrial DNA rearrangements in aging human skeletal muscle. Nucl Acids Res. 1995, 23: 4122-6. 
[31] Clayton D, Williams R, Liang I. Meeting highlights: mitochondrial DNA mutations and cardiomyopathy, heart failure, and ischemic heart disease.Circulation. 1995,92:2022-3.

[32] Ide T, Tsutsui H, Hayashidani S, Kang D, et al. Mitochondrial DNA damage and dysfunction associated with oxidative stress in failing hearts after myocardial infarction. Circ Res. 2001, 88(5):529-35.

[33] Niu T, Xu X, Cordell HJ,et al. Linkage analysis of candidate genes and gene-gene interactions in chinese hypertensive sib pairs.Hypertension. 1999 ,33(6):1332-7.

[34] Corvol P, Persu A, Gimenez-Roqueplo AP, et al. Seven lessons from two candidate genes in human essential hypertension: angiotensinogen and epithelial sodium channel. Hypertension. 1999 ,33(6):1324-31.

[35] Matsubara M. Genetic determination of human essential hypertension. Tohoku J Exp Med. $2000,192(1): 19-33$.

[36] Yang Q, Kim SK, Sun F, et al. Maternal influence on blood pressure suggests involvement of mitochondrial DNA in the pathogenesis of hypertension: the Framingham Heart Study. J Hypertens. 2007,25(10):2067-73.

[37] DeStefano AL, Gavras H, Heard-Costa N, et al. Maternal component in the familial aggregation of hypertension.Am J Hypertens. 2011 Jul 28. doi: 10.1038/ajh.2011.131. [Epub ahead of print]

[38] Puddu P, Puddu GM, Cravero E,et al. The putative role of mitochondrial dysfunction in hypertension. Clin Exp Hypertens. 2007 ,29(7):427-34.

[39] Zhu HY, Wang SW, Martin LJ, er al. The role of mitochondrial genome in essential hypertension in a Chinese Han population. Eur J Hum Genet. 2009,17(11):1501-6.

[40] Levinger L, Morl M, Florentz C. Mitochondrial tRNA 3' end metabolism and human disease. Nucleic Acids Res 2004; 32:5430-41.

[41] Staessen JA, Wang J, Bianchi G, et al. Essential hypertension .Lancet 2003; 361: 1629-41.

[42] Hong Y, de Faire U, Heller DA, et al. Genetic and environmental influences on blood pressure in elderly twins. Hypertension 1994; 24:663-70.

[43] Modi P, Imura H, Angelini GD, et al. Pathology-related troponin I release and clinical outcome after pediatric open heart surgery. J Card Surg 2003; 18:295-300.

[44] Tomari Y, Hino N, Nagaike T, et al. Decreased CCA-addition in human mitochondrial tRNAs bearing a pathogenic A4317G or A10044G mutation. J Biol Chem 2003; 278:16828-33.

[45] Hong KW, Ibba M, Weygand-Durasevic I, et al. Transfer RNA-dependent cognate amino acid recognition by an aminoacyl-tRNA synthetase. EMBO J 1996; 15:198391.

[46] Nagao A, Suzuki T, Suzuki T. Aminoacyl-tRNA surveillance by EF-Tu in mammalian mitochondria. Nucleic Acids Symp Ser (Oxf) 2007; 51:41-2.

[47] Ritz P, Berrut G. Mitochondrial function, energy expenditure, aging and insulin resistance. Diabetes Metab 2005; 2:5S67-73.

[48] Zhu HY, Wang SW, Liu L, et al. A mitochondrial mutation A4401G is involved in the pathogenesis of left ventricular hypertrophy in Chinese hypertensives.Eur J Hum Genet 2009; 17:172-8. 
[49] Clayton D, Williams R, Liang I. Meeting highlights: mitochondrial DNA mutations and cardiomyopathy, heart failure, and ischemic heart disease. Circulation 1995; 92: 2022-3.

[50] Zhu HY, Wang SW, Liu L,et al. Genetic variants in mitochondrial tRNA genes are associated with essential hypertension in a Chinese Han population. Clinica Chimica Acta. 2009.410(1-2):64-9. 


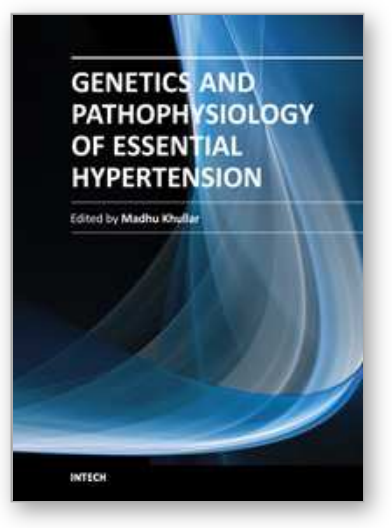

\author{
Genetics and Pathophysiology of Essential Hypertension \\ Edited by Prof. Madhu Khullar
}

ISBN 978-953-51-0282-3

Hard cover, 236 pages

Publisher InTech

Published online 09, March, 2012

Published in print edition March, 2012

This book, authored by renowned researchers in the field of Hypertension Research, details the state of the art knowledge in genetics, genomics and pathophysiology of Essential hypertension, specifically the genetic determinants of hypertension and role of gene variants in response to anti-hypertensive therapy. Two chapters describe mitochondrial mutations in Essential hypertension and in hypertension associated Left ventricular hypertrophy, one chapter reviews in detail the global gene expression in hypertension, and an up to date treatise on pathophysiology of resistant hypertension is detailed in another chapter. Other topics included in the book are end organ damage, baroreceptor sensitivity and role of music therapy in essential hypertension.

\title{
How to reference
}

In order to correctly reference this scholarly work, feel free to copy and paste the following:

Haiyan Zhu and Shiwen Wang (2012). Mitochondrial Mutations in Essential Hypertension, Genetics and Pathophysiology of Essential Hypertension, Prof. Madhu Khullar (Ed.), ISBN: 978-953-51-0282-3, InTech, Available from: http://www.intechopen.com/books/genetics-and-pathophysiology-of-essentialhypertension/mitochondrial-mutations-in-essential-hypertension-

\section{INTECH}

open science | open minds

\section{InTech Europe}

University Campus STeP Ri

Slavka Krautzeka 83/A

51000 Rijeka, Croatia

Phone: +385 (51) 770447

Fax: +385 (51) 686166

www.intechopen.com

\section{InTech China}

Unit 405, Office Block, Hotel Equatorial Shanghai

No.65, Yan An Road (West), Shanghai, 200040, China

中国上海市延安西路65号上海国际贵都大饭店办公楼405单元

Phone: +86-21-62489820

Fax: $+86-21-62489821$ 
(C) 2012 The Author(s). Licensee IntechOpen. This is an open access article distributed under the terms of the Creative Commons Attribution 3.0 License, which permits unrestricted use, distribution, and reproduction in any medium, provided the original work is properly cited. 